\title{
PHYSICAL SORPTION OF MOLECULAR HYDROGEN BY MICROPOROUS ORGANIC POLYMERS
}

\author{
Ivan Saldan ${ }^{1}$ * , Yuliia Stetsiv ${ }^{1}$, Viktoriia Makogon ${ }^{1}$, Yaroslav Kovalyshyn ${ }^{1}$, \\ M ykhaylo Yatsyshyn ${ }^{1}$, O leksandr Reshetnyak ${ }^{1}$
}

https://doi.org/10.23939/chcht13.01.085

\begin{abstract}
The present work describes crosslinked and hypercrosslinked polymers viewed as high surface area materials to adsorb a large amount of molecular hydrogen. Crosslinked polyaniline and polypyrrole were used as examples of hydrogen adsorption by microporous organic polymers. The main reason for physical sorption happening in microporous organic polymers as well the challenges on the way to adjusting the value of hydrogen adsorption enthalpy within the range of $15-20 \mathrm{~kJ} \cdot \mathrm{mol}^{-1} \mathrm{H}_{2}$ are highlighted.
\end{abstract}

Keywords: hypercrosslinked polymers, microporous materials, physical sorption, hydrogen adsorption enthalpy.

\section{Introduction}

Hydrogen has a far higher gravimetric energy density than gasoline, coal, or methane, although gaseous hydrogen has a very low volumetric energy density. To eliminate this disadvantage, two approaches were proposed by scientists and engineers: i) hydrogen storage in the form of chemical hydrides [1] or ammonia [2] and ii) physical storage as compressed, liquefied, or adsorbed molecular hydrogen [3]. Microporous materials (set out by IUPAC pore size within the range of $0.2-2 \mathrm{~nm}$ ) as porous organic polymers can store rather large amounts of hydrogen at the temperatures close to that of liquid nitrogen. It is obvious that maintenance at this temperature in an on-board storage system is inconvenient. Therefore, solutions for storage and release of hydrogen at ambient temperatures are required. Physical sorption of gases, dominated by the interplay between the values of surface area, changes in entropy and enthalpy might be a promising task. However, substantial amounts of hydrogen can be adsorbed only by micropores at about $2-3 \mathrm{~nm}$.

\footnotetext{
${ }^{1}$ Ivan Franko National University of Lviv,

6, Kyryla and Mefodiya St., 79005 Lviv, Ukraine

*saldanivan@gmail.com

(C) Saldan I., Stetsiv Yu., Makogon V., Kovalyshyn Ya., Yatsyshyn M., Reshetnyak O., 2019
}

The main advantages of organic polymers as compared to other porous materials are as follows: i) the possibility to use different reactions for their synthesis; ii) their insensitivity to ambient air; and iii) their mechanical stability as compared to porous carbons and metal-organic frameworks (MOFs). Unfortunately, these materials also have some disadvantages - their exact structures and pore sizes can hardly be evaluated. Additionally, microporous organic polymers adsorb moisture and oxygen when exposed to the atmosphere, but they can easily be regenerated. In the overwhelming majority of materials, only micropores enable to adsorb substantial amounts of molecular hydrogen because of high value of active surface area $\left(4000-4500 \mathrm{~m}^{2} / \mathrm{g}\right)$. Today the hydrogen storage capacity at room temperature and $P\left(\mathrm{H}_{2}\right) \sim 20 \mathrm{MPa}$ for microporous organic polymers reaches the values typical for interstitial metal hydrides, e.g. Ti- or Zr-based alloys, at $P\left(\mathrm{H}_{2}\right) \sim 0.2-0.5 \mathrm{MPa}$ [4-6], that were recommended for reversible electrochemical hydrogen reaction in Ni-MH batteries [7-10]. However, only at lower temperatures $(\sim 77 \mathrm{~K})$ and $P\left(\mathrm{H}_{2}\right) \sim 20 \mathrm{MPa}$ physical adsorption by microporous organic polymers demonstrates hydrogen storage capacity within the range of $\sim 6-7$ wt $\% \mathrm{H}_{2}$, and that becomes reasonable for fuel cell application. Moreover, hydrogen-saturated polymers usually show complete hydrogen desorption at ambient temperatures, which makes them fully reversible. It should be noticed that there are no limitations for fast kinetics in case of reversible hydrogen sorption for microporous organic polymers, while there is only one technical inconvenience - their operation at low temperature.

The present work describes crosslinked and hypercrosslinked polymers viewed as high surface area materials to adsorb a large amount of molecular hydrogen.

\section{Physical Sorption of Molecular Hydrogen}

The Brunauer-Emmett-Teller (BET) equation is well-known in estimating physical adsorption of gas molecules on a solid surface: 


$$
\frac{1}{v\left(\frac{p_{0}}{p}-1\right)}=\frac{c-1}{v_{m} c} \cdot \frac{p}{p_{0}}+\frac{1}{v_{m} c}
$$

where $p_{0}$ and $p$ are the equilibrium and the saturation pressure of adsorbates at the temperature of adsorption, respectively, $\mathrm{Pa} ; \mathrm{v}$ and $v_{\mathrm{m}}$ are the adsorbed gas amount in bulk and in the monolayer, respectively, $\mathrm{m}^{3} ; c$ is BET constant.

The BET approach was designed to overcome the assumption of monolayer coverage required by the Langmuir model [11]. Application of this equation to nitrogen adsorption isotherms is the most common approach to estimate surface area. While it often provides reasonable results, the BET method tends to provide the values that overestimate the surface area of microporous materials due to micropore filling with nitrogen [12]. This effect is most pronounced in pores which are small enough to be filled at low pressures, but still sufficiently large to hold multiple layers of nitrogen. Additionally, this approach does not recognize the pores that are too small and kinetically hindered for diffusion and adsorption of nitrogen at $77 \mathrm{~K}$. Thus, it has become a common way to apply the Langmuir equation to adsorption isotherms of supercritical gases such as hydrogen at $77 \mathrm{~K}$ in order to overcome these shortfalls [13]. The Langmuir approach is based on the assumption that coverage of a surface with supercritical gas will not exceed that of a monolayer, which is generally correct at pressure values up to $0.1 \mathrm{MPa}$. Therefore, it is convenient to use hydrogen as a probe molecule since it enables to detect pores that are too small for nitrogen.

It is well-known that the enthalpy of adsorption determines the temperatures at which reversible adsorption takes place. When the change of adsorption entropy is assumed to be between the entropy of vaporization and $66 \mathrm{~J} \cdot \mathrm{mol}^{-1} \cdot \mathrm{K}^{-1}$ [14], where operating temperature is $298 \mathrm{~K}$, the estimated hydrogen adsorption enthalpy is within the range of $13-20 \mathrm{~kJ} \cdot \mathrm{mol}^{-1}$. The value of $15.1 \mathrm{~kJ} \cdot \mathrm{mol}^{-1}$ became a common enthalpy value for hydrogen storage at room temperature, while $4-7 \mathrm{~kJ} \cdot \mathrm{mol}^{-1}$ - for hydrogen storage at $77 \mathrm{~K}$. In determining the performance of physisorption-based storage systems the average value of pore size is a very important factor as it regulates the relationship between pore volume and surface area and influences adsorption enthalpy significantly. For a given pore volume, the surface area increases as the pore size decreases at any pore geometries. Small pores may enable interactions of the hydrogen molecule with multiple pore walls, resulting in higher values of hydrogen adsorption enthalpy [15]. In the classical approach of pore size distribution determination, the Barrett-Joyner-Halenda (BJH) method is applied to nitrogen adsorption isotherms [16]. The $\mathrm{BJH}$ method is an extension of the Kelvin equation, which relates surface tension to the size of a capillary and the physical properties of an adsorbent [17]:

$$
\ln \left(p / p_{0}\right)=\frac{2 \sigma V_{m}}{r R T}
$$

where $p / p_{\mathrm{o}}$ is relative pressure of the adsorbate; $\sigma$ is the surface tension, $\mathrm{N} / \mathrm{m} ; V_{m}$ is the molar volume of the liquid, $\mathrm{m}^{3} ; R$ is the universal gas constant, $\mathrm{J} \cdot \mathrm{mol}^{-1} \cdot \mathrm{K}^{-1} ; r$ is the radius of a capillary, $\mathrm{m}$; and $T$ is temperature, $\mathrm{K}$.

Nitrogen adsorption at relative pressures of $p / p_{0}=0.25$, together with other values as $p / p_{0}=0.07$ and 0.1 , is sometimes cited as it relies on a measurement that is readily available to most researchers [18]. However, since nitrogen is larger than hydrogen both in the gas phase and in the adsorbed phase, all nitrogen-based analyses neglect pores that are too small for nitrogen adsorption but large enough for hydrogen adsorption. In addition to that, micropore volume can also be estimated on the basis of $\mathrm{CO}_{2}$ adsorption at $273 \mathrm{~K}$. Moreover, the correlation between hydrogen storage capacity and $\mathrm{CO}_{2}$ micropore volume in porous carbons has been suggested [19]. Other approaches to determine micropore volumes include a plot of the volume of gas adsorbed as a function of statistical thickness of the adsorbed film ( $t$-plot), or Dubinin-Radushkevich approach [20]:

$$
\ln W=\ln W_{0}-D \ln ^{2}\left(p / p_{0}\right)
$$

where $W$ and $W_{\mathrm{o}}$ are, the filled and total adsorption volume, respectively, $\mathrm{m}^{3} ; D=k R^{2} T^{2} / \beta^{2}$ with constant $k$ and affinity coefficient $\beta$. The $t$-plot method is used with the Halsey thickness equation [21]:

$$
t=a\left(\frac{1}{\ln \left(p_{0} / p\right)}\right)^{1 / b}
$$

where $t$ is thickness of the adsorbed film, $\AA$; the pre-factor $a$ and the exponent $b$ can be obtained by applying the Frenkel-Halsey-Hill approach.

Unfortunately, BJH method cannot be used for materials with small pores as it relies on details of meniscus formation, which change with the decrease in dimension [22]. Therefore, alternative methods have been developed to analyze materials with pores smaller than $5 \mathrm{~nm}$, e.g. the density functional theory (DFT) [23] and the Horvath-Kawazoe method [24].

Positron annihilation lifetime spectroscopy (PALS) and small angle X-ray scattering (SAXS) are the most common non-sorption-based methods of micropore identification [25]. The PALS method is successfully used to examine mainly porous polymers. Bound pairs of positrons and electrons, generated at PALS, encountering pore walls can force them to annihilate. Thus, pore size can be estimated as a function of the time span needed for positron annihilation. In SAXS, part of a monochromatic beam of X-rays is scattered by a sample. The technique 
relies on scattering by small species to provide information on the material nanostructure. SAXS was applied to porous silica, porous carbons and porous polymers. While the surface area is often a convenient access for adsorption sites and can be used to get a fast evaluation of hydrogen storage capacity, pore volume presents substantial limitations. For the case of physisorption at supercritical temperatures, the density of stored hydrogen is expected to be lower than that of liquid hydrogen. It is relevant for the majority of microporous hydrogen storage materials and can be used to define a saturation limit for hydrogen adsorption in such materials. However, this limitation does not apply when chemisorption or a chemical reaction takes place between hydrogen and substrate [26]. Today there is no agreement concerning the reasonable size of pores to be employed at reversible hydrogen sorption, although pores diameter about $2-3 \mathrm{~nm}$ seems to be a compromise solution. There are two main factors for finding the reasonable size of pores for hydrogen adsorption: i) when the pore size increases, the value of adsorption enthalpy decreases; ii) when the square of pore size increases, the density of pores decreases. Thus, the saturation limit for hydrogen physisorption in microporous material used under supercritical conditions can be estimated as the product of the micropore volume and the density of liquid hydrogen. It should be noted that the limit of adsorption defined by the micropore volume refers to total adsorption (the total amount of hydrogen stored in the pores) rather than to excess adsorption that represents the difference between the total hydrogen stored and the amount that would be stored in the same volume with no adsorption. It is clear that total and excess hydrogen storage might be approximately the same at low pressures while they differ a lot at high pressures.

Both volumetric and gravimetric hydrogen adsorption measurements rely on the assumption that porous material does not adsorb helium. Therefore, in the case of volumetric method, the free space in the sample holder is usually measured using the known quantity of helium, while in the case of gravimetric method helium is used to quantify the skeletal density of the sample. However, in some cases microporous materials do adsorb small amounts of helium [27], and this adsorption results in the underestimation of hydrogen storage capacity since the free space of the sample holder is overestimated while skeletal density is underestimated. No complete experimental solution to the problem of helium adsorption has been proposed yet. At reasonably attainable pressures helium adsorption might be described by Henry's law, which states that the amount of dissolved gas is proportional to its partial pressure in the gas phase:

$$
K_{H}=\frac{P}{C_{a}}
$$

where $K_{H}$ is the Henry volatility, $\mathrm{Pa} \cdot \mathrm{m}^{3} / \mathrm{mol} ; P$ is partial pressure, $\mathrm{Pa} ; C_{a}$ is aqueous phase concentration, $\mathrm{mol} / \mathrm{m}^{3}$.

Therefore, free space errors would be minimized through performance of helium-related measurements at the lowest pressure. It is also suggested that skeletal density measurements should be performed at high temperatures [27], but this is applicable to materials with a very small thermal expansion coefficient.

\section{Cross- and Hypercrosslinked Organic Polymers}

In porous organic polymers pores are generated via inclusion of porogen, which is typically an inert solvent, in the polymerization mixture [28]. Porogens that are more thermodynamically compatible with monomers are used to form small pores, while those that are less compatible - to form large pores. For example, polymerization of pentaerythritol triacrylate (PETrA) in xylene, which has a polymer-porogen affinity parameter $\delta=14 \mathrm{MPa}^{1 / 2}$, produces a material with an average pore size of $\sim 5 \mathrm{~nm}$ and the surface area of $\sim 228 \mathrm{~m}^{2} / \mathrm{g}$, while the same polymerization in butyl acetate $\left(\delta=9 \mathrm{MPa}^{1 / 2}\right)$ produces a material with a pore size of $\sim 3.5 \mathrm{~nm}$ and the surface area of $\sim 471 \mathrm{~m}^{2} / \mathrm{g}$ under the same conditions [29]. Crosslinked porous polymers show a higher value of specific surface areas that is within the range of 1000 $1200 \mathrm{~m}^{2} / \mathrm{g}$ [30-32]. These materials are typically synthesized through suspension polymerization [32-34], although they can also be prepared via precipitation or seeded polymerization $[35,36]$, even in a monolithic format [37]. Hypercrosslinked organic polymers have a very fine pore structure made of a special network of monomers or small molecules. Fig. 1 schematically shows that a lightly attached precursor is first swollen or dissolved in a solvent resulting in a space between polymer chains. The precursor is then crosslinked so that the majority of repeated units are linked to their neighbours by at least three bonds. Rapid crosslinking maintains polymer chains locked in an expanded form. Finally, when the solvent is removed from the reaction mixture, a porous structure of hypercrosslinked organic polymers can be obtained [38].

The first hypercrosslinked polymers were derivatives of polystyrene and after that polysulfones and polyarylates [39], poly(vinylpyridines) [40], and even polyanilines [38] were hypercrosslinked to provide materials with substantial surface area.

Crosslinked poly(styrene-codivinylbenzenes) and their derivatives were the first large-surface-area porous polymers tested for hydrogen storage at $77 \mathrm{~K}$ [13]. Some of them are shown in Table 1 [3]. 


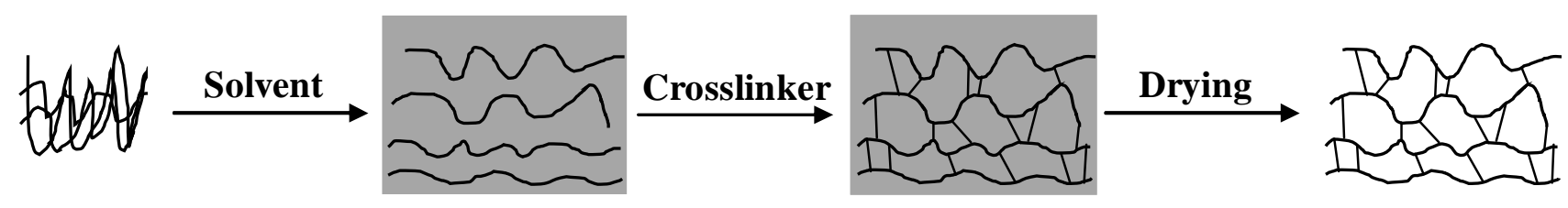

Fig. 1. A general scheme of the preparation of hypercrosslinked organic polymers. Adapted with permission from [38]

Table 1

Experimental values* of surface area and hydrogen storage capacity of the first crosslinked polymers

\begin{tabular}{|c|c|c|c|c|}
\hline \multirow{2}{*}{$\begin{array}{c}\text { Commercial name } \\
\text { Hypersol-Macronet } \\
\text { MN500 }\end{array}$} & Chemical name & \multicolumn{2}{|c|}{ Surface area, $\mathrm{m}^{2} / \mathrm{g}$} & \multirow{2}{*}{$\begin{array}{c}\text { Hydrogen adsorption, } \\
\mathrm{wt}_{\%} \mathrm{H}_{2}^{(c)}\end{array}$} \\
\cline { 2 - 4 } & $\mathrm{BET}^{(a)}$ & Langmuir $^{(b)}$ & 0.7 \\
\hline Lewatit VP OC 1064 & Poly(styrene-co-divinylbenzene) & 810 & 377 & 0.7 \\
\hline Amberlite XAD4 & Poly(styrene-co-divinylbenzene) & 1060 & 425 & 0.8 \\
\hline $\begin{array}{c}\text { Hypersol-Macronet } \\
\text { MN100 }\end{array}$ & $\begin{array}{c}\text { Amine functionalized hypercrosslinked } \\
\text { polystyrene }\end{array}$ & 600 & 477 & 1.1 \\
\hline Wofatit Y77 & Poly(styrene-co-divinylbenzene) & 940 & 573 & 1.2 \\
\hline Lewatit EP63 & Poly(styrene-co-divinylbenzene) & 1206 & 664 & 1.3 \\
\hline $\begin{array}{c}\text { Hypersol-Macronet } \\
\text { MN200 }\end{array}$ & Hypercrosslinked polystyrene & 840 & 576 & 1.3 \\
\hline
\end{tabular}

Notes: * Reproduced with permission from [3]; (a) calculated from nitrogen adsorption isotherms using the BET equation; $(b)$ calculated from hydrogen adsorption using the Langmuir equation; (c) hydrogen storage capacity at $77 \mathrm{~K}$ and $0.12 \mathrm{MPa}$.

It should be noted that the correlation between the surface area values and adsorbed hydrogen values suggests availability of different type of interactions for the various materials. It was found that polymers based on networks of aromatic rings can adsorb more hydrogen in both total and per unit surface area. In particular, it was observed experimentally that under the same conditions hypercrosslinked polystyrenes like Hypersol-Macronet MN200 adsorb more hydrogen than poly(styrene-codivinylbenzene) chains such as Amberlite XAD4, even if the latter exhibits higher surface areas [13]. Additionally, when at $77 \mathrm{~K}$ the value of $P\left(\mathrm{H}_{2}\right)$ changed from 0.12 to 3.0 MPa [41] or to $8.0 \mathrm{MPa}$ [42], the hydrogen storage capacity of hypercrosslinked polystyrenes increased to 3.0 or $5.4 \mathrm{wt} \% \mathrm{H}_{2}$, respectively.

The HCl-treated polyaniline (PAn) and polypyrrole (PPy) were also tested in terms of their usage as $\mathrm{H}_{2}$ adsorbers. Surprisingly, their value of hydrogen storage capacity was within the range of $6-8 \mathrm{wt} \% \mathrm{H}_{2}$ at ambient temperature [43], although these results were not reproducible in practice [44]. The studies of hydrogen adsorption for mesoporous samples with the specific surface area of $\sim 50 \mathrm{~m}^{2} \cdot \mathrm{g}^{-1}$ confirmed hydrogen uptake of $\sim 2.2 \mathrm{wt} \% \mathrm{H}_{2}$ at $9 \mathrm{MPa}$ and $77 \mathrm{~K}$ [45]. This is highly noticeable since hydrogen adsorption of porous materials at $77 \mathrm{~K}$ typically follows the trend of $\sim 1 \mathrm{wt} \% \mathrm{H}_{2}$ per $\sim 500 \mathrm{~m}^{2} \cdot \mathrm{g}^{-1}$ (the so-called Chahine's rule [46]). PAn as a hydrogen sensor [47-49] suggests that there is certain interaction between gaseous hydrogen and doped PAn at room temperature. PAn is one of the most extensively studied conducting polymers due to interesting redox properties associated with nitrogen heteroatoms and the conjugation of $\pi$-electrons. Its low cost, good stability and high electrical conductivity make PAn environmentally friendly and very popular and [50-57]. Crosslinked PAn with a porous structure has been developed due to a great attention paid to ordered mesoporous and nanoporous materials [38, 58-61]. The crosslinking reactions for PAn might be carried out using diiodoalkanes or paraformaldehyde [38], $\alpha, \alpha$ 'dichloro- $p$-xylene or glutaraldehyde [62], or surfactant-forming micelles [63]. A crosslinking process for PAn was proposed via thermal treatment with no use of crosslinkers [64]. This process results in the presence of tertiary amine nitrogen atoms yielding an $N, N$ '-diphenylphenazine structure at the site of crosslinking [65]. Later it was found that PAn undergoes some changes upon thermal treatment, including dedoping, oxidation, chain scission, crosslinking and, finally, changes in the crystal structure [66-73]. For example, conversion of quinonoid to benzenoid rings upon heating at $\sim 473 \mathrm{~K}$ in vacuum was confirmed in practice [74]. To increase the value of the active surface area for PAn, nanostructured PAn such as nanotubes or nanoparticles were proposed in [75-77]. At $398 \mathrm{~K}$ PAn nanocomposites can store less than $0.5 \mathrm{wt} \% \mathrm{H}_{2}$ [78]. A slight increase in hydrogen adsorption of the material was 
visible because of increase in porosity. Composites made of tin oxide and PAn showed no difference in hydrogen adsorption as compared to pure PAn. Inclusion of multiwall carbon nanotubes (MWCNT) showed some effect, while addition of aluminum fine powder demonstrated quite a big effect on the value of hydrogen storage capacity. Experimental FTIR data confirmed chemical interaction only between the aluminum powder and PAn, though reaction products were studied. In another work the MWCNT-PAn-Ni composite was synthesized as a promising hydrogen-storage material, though no hydrogen test was made in practice [79]. The interaction between MWCNT and PAn after addition of nickel powder was confirmed by a shift in the IR signal of $\mathrm{NH}$ vibrations, though a detailed analysis of the interaction between all components in MWCNT-PAn-Ni composite is still needed. In [80] the FTIR spectra showed that the chemical composition of $\mathrm{HCl}$-doped PAn samples can be altered through thermal treatment. In addition, it was suggested that conductometric measurement can be exploited as a useful tool for systematic screening of active chemical species derived from conducting polymers or their composites for hydrogen storage. Nanofibers with the diameter within the range of 70 $90 \mathrm{~nm}$ and the length of $0.5-1 \mu \mathrm{m}$ and the value of active surface area of $68.4 \mathrm{~m}^{2} / \mathrm{g}$, synthesized in [81] PAn, showed electrical conductivity value of $3.46 \mathrm{~S} / \mathrm{cm}$. The hydrogen sensor based on PAn nanofibers showed high sensitivity and a short response time. The limit of detection and limit of quantification of the hydrogen sensor were 40 and $133 \mathrm{ppm}$ of $\mathrm{H}_{2}$, respectively. Emeraldine salt (ES) with the imine nitrogen atoms protonated by sulphuric acid (Fig. 2a) that promotes delocalization of diiminoquinone-diaminobenzene state of the salt form of PAn has an open nanofiber structure. Degree of the protonation and size of doping anion are responsible for selectivity and permeability of PAn resulting in different gas-transport for common gasses like oxygen, nitrogen and hydrogen [82]. Crosslinked PAn with anthraquinone derivative (Fig. 2b) and an azo dye with a large $\pi$-conjugated structure and three sulfonate anions (Acid Red 27) demonstrates a chain segment of PAn arranged closely [57].

In case of crosslinked PAn, Acid Red 27 was used as the crosslinking agent and sulphuric acid was used as the doping agent for ES formation. When the molar ratio of Acid Red 27 to aniline was 0.01:1, the crosslinking density of the crosslinked PAn was low, so that it could not easily precipitate from the reaction mixture until the diameter of fiber was $\sim 300 \mathrm{~nm}$. At the same time, the chain segment of PAn would extend out of the fiber surface to form ES because of the low crosslinking density. In other words, in case of the increase in the crosslinking agent, the thin fiber could easily precipitate and the chain segments of PAn are arranged closely to form the crosslinked PAn fiber with a smooth surface. Because of high porosity this crosslinked PAn can be proposed as an effective $\mathrm{H}_{2}$ adsorber at $77 \mathrm{~K}$.

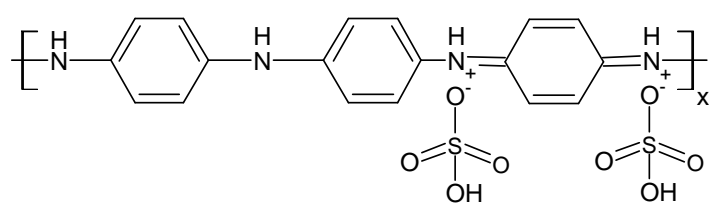

a)

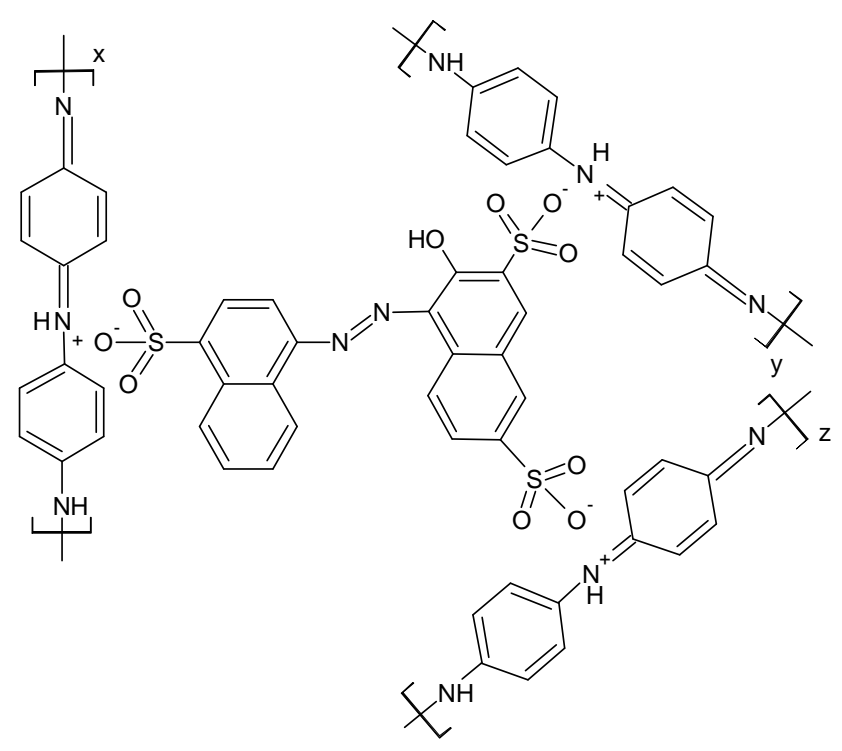

b)

Fig. 2. PAn protonated by sulphuric acid (a) and crosslinked by Acid Red 27 (b). Adapted with permission from [57]

PPy is another good example of hydrogen adsorption by microporous organic polymers. In general, chemical and physical properties of PPy are quite similar to those of PAn, however there are some differences [8390]. Porous structure of PPy was studied by BET and BJH method in [83]. It was found that electrochemically synthesized PPy films have rather mesoporosity (pore diameter within 2-20 nm), than microporosity. This experimental result might explain lower mobility of larger ions in PPy layers soaked in electrolyte. It was concluded that properties of dopant ions have no effect on the average pore diameter of PPy $(1.7-1.9 \mathrm{~nm})$, while they showed a considerable influence on the values of the pore volume and the specific surface area. A compact structure of PPy films containing large oligomeric surfactants (e.g. dodecylsulfate and naphthalene (di)sulfonate anions) was explained by a better film package and more effective occupation of the void space in PPy by big dopants. Small hydrophilic inorganic anions promoted PPy films two times more sparse than large anionic surfactants. 
Depending on the synthesis conditions and the degree of PPy oxidation, PPy films $(<1 \mathrm{~mm})$ show different spectral properties [84, 88, 89]. Adhesion of PPy films depends on a number of factors including the nature, coarseness, hydrophobicity of the solid electrode surface, and the solvent [84]. Stability of the doped PPy films in the air is relatively high and depends on the doping agent resulting in their degradation within the temperature range of $423-573 \mathrm{~K}$. Thermal stability of PPy films prepared through electropolymerization improves after their treatment with $\left(\mathrm{SO}_{4}\right)^{2-}$ anion. The films of reduced PPy are unstable in the air, therefore they change their transparent and yellow colour into a dark one and irreversibly lose their ability to undergo redox transition. PPy doped with an anthraquinone derivative could exhibit improved electrochemical performance due to its special structure with high porosity and large specific surface area [90]. The anthraquinone and sulfonate dopants can generate more hydrophilic surfaces with a submicron/nano-sized structure, which results in a higher value of the surface area of PPy composites, moreover, immobilized anthraquinone groups themselves show fast redox electrochemistry.

Microporous organic polymers which exhibit sizeselective gas adsorption might consist of chains of aromatic rings crosslinked at trivalent nitrogen atoms, contain numerous pores that can adsorb hydrogen but are too small for nitrogen penetration. The use of doped polypyrrole as a material for hydrogen storage has also been suggested, although the promising value of hydrogen adsorption on nonporous polymers could not be reproduced. Crosslinking reactions for PPy with diiodomethane, iodoform and boron triiodide were used in [91] for the first time (Fig. 3).

At $77 \mathrm{~K}$ and $0.4 \mathrm{MPa}$ of $\mathrm{H}_{2}$ the hydrogen storage capacity values for the PPy crosslinked by diiodomethane, iodoform and boron triiodide were experimentally obtained as 1.6, 1.3 and 0.63 wt $\% \mathrm{H}_{2}$. Moreover, these values correlated well with those of the surface area that were calculated from hydrogen adsorption isotherms using the Langmuir adsorption model. Using "solid-state vapor-phase polymerization method" [92], mesoporous PPy with sponge-like pockets was synthesized to be used as hydrogen storage material in [45]. The preparation method was responsible for the pore diameter of mesoporous PPy. It was found that the values of hydrogen storage capacity and pore volume decreased with the increase of reaction time. Experimental values of hydrogen storage capacity and heat of adsorption were $2.2 \mathrm{wt} \% \mathrm{H}_{2}$ at $77 \mathrm{~K}$ and $7.51 \mathrm{~kJ} / \mathrm{mol}$, respectively. Keeping identical mass ratio of pyrrole monomer and carbon nanotubes (CNT), spherical PPy structures were synthesized, and with a higher amount of pyrrole monomer - layer-by-layer formations were synthesized on the CNT surface [93]. Oxygen functionalization of CNT through acid treatment resulted in a homogeneous PPy coverage and thus agglomeration of PPy spheres was prevented. In that case wall thickness increased gradually with pyrrole feeding mass ratio increase. Increased PPy amount caused a decrease in the crystallinity of CNT-PPy composites as well as BET surface area and BJH pore size. On the other hand, PPy-coated CNT bundles formed new adsorption sites between the nanotube arrays for hydrogen molecules. That is why CNT-PPy composites might adsorb three times more hydrogen than pristine $\mathrm{CNT}$ at room temperature. Finally, it was concluded that untreated CNT should demonstrate weak van der Waals interactions between hydrogen molecules, while oxidized CNT or CNT-PPy composite suggested the ability to store hydrogen chemically since a hysteresis loop was observed between the adsorption and desorption curves. In other words, this originated from an increase in $\mathrm{sp}^{2}$ bonds after the oxidation process, defective and amorphous surfaces, and higher binding energies of chemisorbed hydrogen.

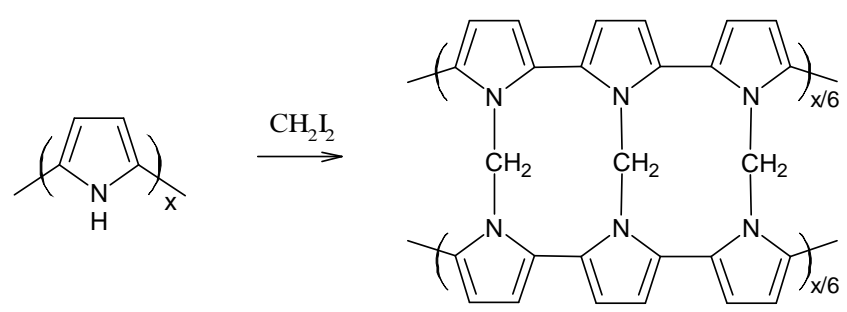

a)
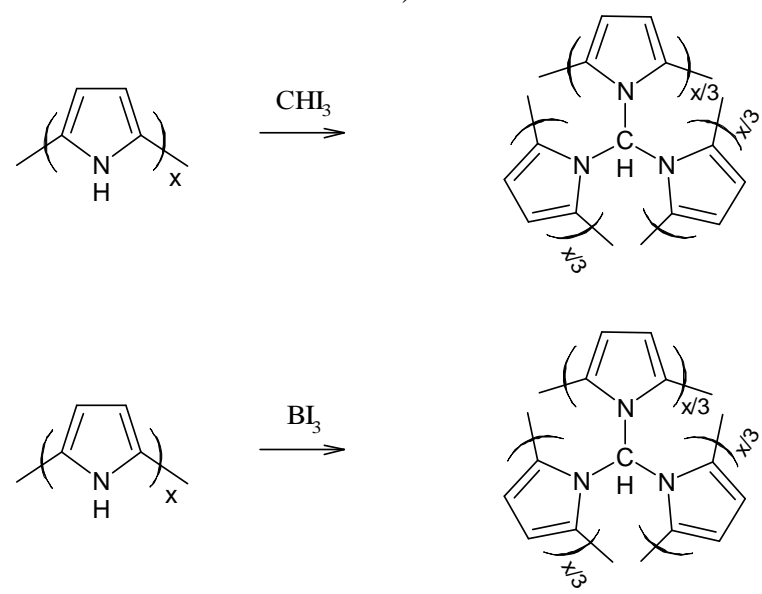

b)

Fig. 3. Crosslinking reactions for PPy via $N$-alkylation with diiodomethane (a) in the presence of sodium tert-butoxide and in the presence of caesium carbonate with iodoform (b) and boron triiodide (c). Adapted with permission from [91]

The synthesis of PAn-PPy composites was developed on the basis of PAn nanofibers covered with a 
thin layer of PPy via vapor phase polymerization [94]. The hydrogen storage capacity of the composites was evaluated at room temperature and showed a two times higher value where $\mathrm{HCl}$-doped $\mathrm{PAn}$ nanofibers demonstrated $0.46 \mathrm{wt} \% \mathrm{H}_{2}$ and PAn-PPy composites $0.91 \mathrm{wt} \% \mathrm{H}_{2}$. Higher value of hydrogen storage capacity was found for the composite where palladium nanoparticles were located between PAn nanofibers and the PPY layer. Analysing the effect of every component in PAn-PPy composites, a conclusion was made that higher hydrogen uptake was attributed to the introduction of the PPY layer through a large number of adsorption sites for hydrogen molecules. Consequently, reasonable modified PAn and/or PPy composites might be a promising solid state system for hydrogen storage due to their high volumetric/gravimetric capacity and fast adsorption kinetics at ambient conditions.

\section{M icroporous Organic Polymers as Room Temperature Hydrogen Storage Materials}

Detailed analysis of the total hydrogen storage capacity and pore volume of microporous organic polymers confirmed that experimentally observed hydrogen adsorption might approach the value of liquid hydrogen density under the same saturation conditions. Calculated adsorption enthalpy of crosslinked polyfunctional benzyl chlorides was $7.5 \mathrm{~kJ} \cdot \mathrm{mol}^{-1}$ [95], that is even higher as compared to hypercrosslinked polystyrenes $\left(6.6 \mathrm{~kJ} \cdot \mathrm{mol}^{-1}\right.$ [42]). The studies of hypercrosslinked polystyrenes have demonstrated that they can store significant amounts of hydrogen at cryogenic temperatures, but they demonstrate a small hydrogen storage capacity at room temperature. Although it was difficult to distinguish the effects of swelling and the electron density on hydrogen adsorption characteristics, addition of electron-donating groups and introduction of smaller pores was used as possible approach aimed at bringing the value of hydrogen adsorption enthalpy to the range of $15-20 \mathrm{~kJ} \cdot \mathrm{mol}^{-1} \mathrm{H}_{2}$, suggested for reversible hydrogen storage at room temperature. It was shown that aromatic rings might be a primary adsorption site in the materials that lack metal coordination sites [96, 97], and it was suggested that addition of electron-donating groups to the aromatic ring may increase interaction between polymer and molecular hydrogen [98]. A prominent example is deprotonated amine in PAn as a strong electron-donating group that increases hydrogen adsorption, while low ability to adsorb hydrogen molecules was found when this amine became electron-withdrawing via protonation (Fig. 4).

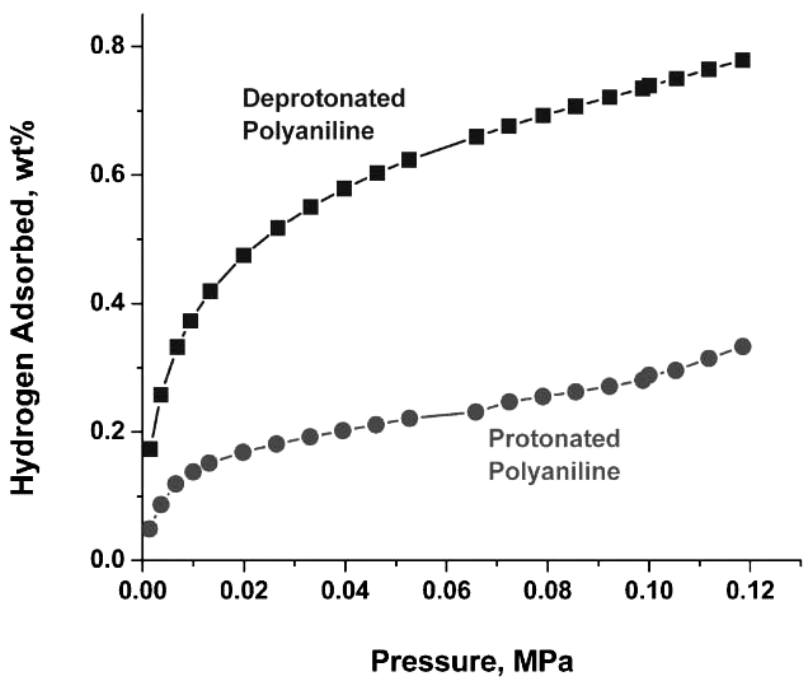

Fig. 4. Hydrogen adsorption isotherms measured using leucoemeraldine form of PAn hypercrosslinked using diiodomethane before (squares) and after (circles) protonation with $\mathrm{HCl}$ at $P\left(\mathrm{H}_{2}\right)$ of $0.12 \mathrm{MPa}$. Reprinted with permission from [38]

Since the most common value of adsorption enthalpy for microporous organic polymers is located within the range of $5-7 \mathrm{~kJ} \cdot \mathrm{mol}^{-1} \mathrm{H}_{2}$, screening of approaches to increasing the enthalpy value approximately three times is required. Today, the socalled "spillover effect", adsorption in very small pores and adsorption in unsaturated metal centers are suggested as the most recommended ones for all types of porous materials. In fact, the spillover effect has long been used to perform hydrogenation of many organic compounds. During spillover hydrogen molecules might be adsorbed chemically in a metal catalyst (typically, that is $\mathrm{Pt}, \mathrm{Pd}$, or any other noble metal), where they dissociate to hydrogen atoms and are transported to the surface. In literature the spillover effect is divided into two processes: i) the socalled "primary spillover" - hydrogen atoms stay on the surface nearby the metal catalyst; and ii) "secondary spillover" - hydrogen atoms move to the second surface [99]. For both spillover processes the limit of hydrogen uptake is the function of the number of adsorption sites in a porous material, which depends on the surface area value. Initial works on the spillover effect produced high expectations but they almost disappeared due to nonrepetition of such results. Therefore, a better understanding of the primary and secondary spillover processes is absolutely necessary.

In large-pore hydrogen molecules can interact with only one wall. However, when a pore is very small, the molecule is close enough to multiple pore walls, which results in a higher adsorption enthalpy value. The generation of small pores results in higher values of adsorption enthalpies, but lower values of the surface area 
and pore volume. Therefore, production of materials that possess combined attributes required for high adsorption enthalpy with a large surface area and pore volume remains a difficult task. Hypothetically, using hypercrosslinking would likely require the use of a fast non-catalyzed crosslinking reaction that takes place unhindered in a solvent thermodynamically compatible with all precursors.

Adsorption in unsaturated metal or boron centers is affected by the difficulties in the production of materials with large quantities of such unsaturated centers. Frequently, the conditions required for dissolution of these metal centers can approach the ones that have a negative impact on the framework, requiring a compromise between hydrogen storage capacity and framework integrity.

Nevertheless, one decade ago a series of microporous organic polymers consisting of aromatic rings connected by trivalent- and single-atom crosslinkers was prepared using these approaches to increase adsorption enthalpy value (Fig. 5).

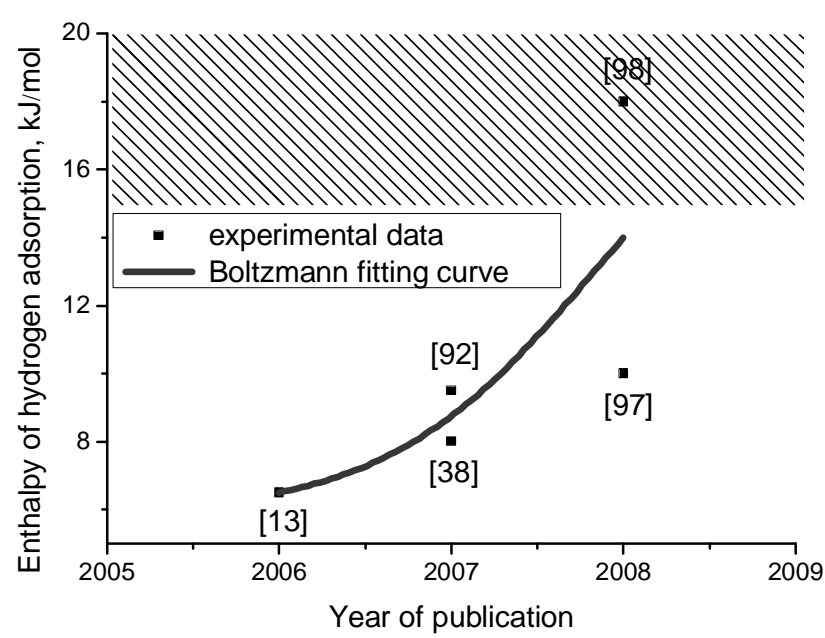

Fig. 5. Experimental values of the enthalpy of hydrogen adsorption with the corresponding references published in 2006-2008. Highlighted range of $15-20 \mathrm{~kJ} \cdot \mathrm{mol}^{-1} \mathrm{H}_{2}$ are desired values of the enthalpy of hydrogen adsorption for room temperature hydrogen storage by microporous organic polymers.

Adapted with permission from [3]

Cooper et al. [100] managed to achieve $10 \mathrm{~kJ} \cdot \mathrm{mol}^{-1} \mathrm{H}_{2}$ by packing aromatic rings with high density into a porous polymer. Experimental results in [101] suggest adsorption enthalpy values close to $18 \mathrm{~kJ} \cdot \mathrm{mol}^{-1} \mathrm{H}_{2}$ at low coverages. Small size of the pores found in these materials constituted the reason for adsorbing only molecular hydrogen in practice, excluding nitrogen gas. It should be noted that these types of polymers might be considered as interpenetrating networks in which the distance between aromatic rings should be considered to estimate pore size.

\section{Conclusions}

Reviewed experimental results suggest that microporous organic polymers can approach the capacities required by DOE for hydrogen storage. In fact, hypercrosslinked polymers have been synthesized with hydrogen storage capacities equal to more than $6 \mathrm{wt} \% \mathrm{H}_{2}$ [102]. The success of these materials has demonstrated that the surface area, pore volume, and pore size are all important for storage hydrogen molecules [103]. Unfortunately, microporous organic polymers might be considered as hydrogen storage materials only at cryogenic temperatures. Since hydrogen storage at $77 \mathrm{~K}$ is more energy efficient than liquefaction of hydrogen at 20 $\mathrm{K}$, it has a limited feasibility for practical use of polymers at low temperature. Thus, the main challenge for microporous organic polymers is their reversible operation as hydrogen storage materials at room temperature.

\section{Acknowledgements}

The authors thank for the financial support from project (reference number 0117U001235) provided by the Ministry of Education and Science of Ukraine.

\section{References}

[1] Callini E., Atakli Z., Hauback B. et al.: Appl. Phys. A, 2016, 122, 353. https://doi.org/10.1007/s00339-016-9881-5

[2] Klerke A., Christensen C., Nørskov J., Vegge T.: J. Mater. Chem., 2008, 18, 2304. https://doi.org/10.1039/B720020J

[3] Germain J., Frechet J., Svec F.: Small, 2009, 5, 1098. https://doi.org/10.1002/smll.200801762

[4] Zavaliy I., Yelon W., Zavalij P. et al.: J. Alloy. Compd., 2000, 309, 75. https://doi.org/10.1016/S0925-8388(00)00899-9

[5] Zavaliy I., Černý R., Kovalchuck I., Saldan I.: J. Alloy. Compd., 2003, 360, 173. https://doi.org/10.1016/S0925-8388(03)00376-1

[6] Saldan I., Frenzel J., Shekhah O. et al.: J. Alloy. Compd., 2009, 470, 568. https://doi.org/10.1016/j.jallcom.2008.03.050

[7] Saldan I., Kovalchuk I., Zavalii I.: Mater. Sci., 2003, 39, 545. https://doi.org/10.1023/B:MASC.0000010933.80070.a9aszszZ [8] Saldan I., Dubov Yu., Ryabov O., Zavalii I.: Mater. Sci., 2006, 42, 634. https://doi.org/10.1007/s11003-006-0127-0

[9] Saldan I., Burtovyy R., Becker H.-W. et al.: Int. J. Hydrogen Energ., 2008, 33, 7177.

https://doi.org/10.1016/j.ijhydene.2008.09.002

[10] Saldan I.: J. Solid State Electrochem., 2010, 14, 1339.

https://doi.org/10.1007/s10008-009-0974-3

[11] Sing K., Williams R.: Adsorp. Sci. Technol., 2004, 22, 773. https://doi.org/10.1260/0263617053499032

[12] Kaneko K., Shimizu K.: J. Chem. Phys., 1992, 97, 8705. https://doi.org/10.1063/1.463389

[13] Germain J., Hradil J., Frechet J., Svec F.: Chem. Mater., 2006, 18, 4430. https://doi.org/10.1021/cm061186p

[14] Bhatia S.: Langmuir, 2006, 22, 1688.

https://doi.org/10.1021/la0523816

[15] Wang Q., Johnson J.: J. Chem. Phys., 1999, 110, 577. https://doi.org/10.1063/1.478114 
[16] Villarroel-Rocha J., Barrera D., Sapag K.: Micropor. Mesopor. Mat., 2014, 200, 68.

https://doi.org/10.1016/j.micromeso.2014.08.017

[17] Barrett E., Joyner L., Halenda P.: J. Am. Chem. Soc., 1951, 73, 373. https://doi.org/10.1021/ja01145a126

[18] Texier-Mandoki N., Dentzer J., Piquero T. et al.: Carbon, 2004, 42, 2744. https://doi.org/10.1016/j.carbon.2004.05.015

[19] Gadiou R., Texier-Mandoki N., Piquero T. et al.: Adsorption, 2005, 11, 823. https://doi.org/10.1007/s10450-005-6030-4

[20] Marsh H., Rand B.: J. Colloid Interf. Sci., 1970, 33, 101. https://doi.org/10.1016/0021-9797(70)90077-9

[21] Dubinin M.: Carbon, 1989, 27, 457.

https://doi.org/10.1016/0008-6223(89)90078-X

[22] Kaneko K.: J. Membrane Sci., 1994, 96, 59.

https://doi.org/10.1016/0376-7388(94)00126-X

[23] Tarazona P.: Phys. Rev. A, 2006, 31, 2672.

https://doi.org/10.1103/PhysRevA.31.2672

[24] Horvath G., Kawazoe K.: J. Chem. Eng. Jpn., 1983, 16, 470. https://doi.org/10.1252/jcej.16.470

[25] Zhang C., Babonneau F., Bonhomme C. et al.: J. Am. Chem.

Soc., 1998, 120, 8380. https://doi.org/10.1021/ja9808853

[26] Liu Y., Kabbour H., Brown C. et al.: Langmuir, 2008, 24,

4772. https://doi.org/10.1021/la703864a

[27] Malbrunot P., Vidal D., Vermesse J. et al.: Langmuir, 1997, 13, 539. https://doi.org/10.1021/la950969e

[28] Seidl J., Malinský J., Dušek K., Heitz W.: Adv. Polym. Sci., 1967, 5, 113. https://doi.org/10.1007/BFb0051281

[29] Rohr T., Knaus S., Gruber H., Sherrington D.:

Macromolecules, 2002, 35, 97. https://doi.org/10.1021/ma0110958

[30] Maillardterrier M., Cazé C.: Eur. Polym. J., 1984, 20, 113.

https://doi.org/10.1016/0014-3057(84)90195-2

[31] Nyhus A., Hagen S.: J. Polym. Sci. A, 1999, 37, 3973.

https://doi.org/10.1002/(SICI)1099-

0518(19991101)37:21<3973::AID-POLA12>3.0.CO;2-X

[32] Okay O.: Prog. Polym. Sci., 2000, 25, 711.

https://doi.org/10.1016/S0079-6700(00)00015-0

[33] Guyot A., Bartholin M.: Prog. Polym. Sci., 2008, 8, 277.

https://doi.org/10.1016/0079-6700(82)90002-8

[34] Sherrington D.: Chem. Commun., 1998, 21, 2275.

https://doi.org/10.1039/A803757D

[35] Li W., Stover H.: J. Polym. Sci. A, 1998, 36, 1543.

https://doi.org/10.1002/(SICI)1099-

0518(19980730)36:10<1543::AID-POLA7>3.0.CO;2-R

[36] Cheng C., Micale F., Vanderhoff J., El Aasser M.: J. Polym.

Sci. A, 1992, 30, 235. https://doi.org/10.1002/pola.1992.080300208

[37] Svec F., Frechet J.: Anal. Chem., 1992, 54, 820.

https://doi.org/10.1021/ac00031a022

[38] Germain J., Frechet J., Svec F.: J. Mater. Chem., 2007, 17, 4989. https://doi.org/10.1039/B711509A

[39] Tsyurupa M., Davankov V.: React. Funct. Polym., 2002, 53,

193. https://doi.org/10.1016/S1381-5148(02)00173-6

[40] Pavlova L., Pavlov M., Davankov V.: Dokl. Chem., 2006, 406, 6. https://doi.org/10.1134/S0012500806010022

[41] Lee J., Wood C., Bradshaw D. et al.: Chem. Commun., 2006, 2670. https://doi.org/10.1039/B604625H

[42] Germain J., Svec F., Fréchet J.: Proceedings of a Massachusetts Meeting. Polymeric Materials: Science and Engineering Preprints.

USA, Boston 2007, 97, 272.

[43] Cho S., Kwang S., Kim T., Choo K.: $224^{\text {th }}$ ACS National Meeting. USA, Boston 2002, 47, 790.

[44] Panella B., Kossykh L., Dettlaff-Weglikowsa U. et al.: Synth. Met., 2005, 151, 208.

https://doi.org/10.1016/j.synthmet.2005.05.004
[45] Attia N., Lee S., Kim H., Geckeler K.: Int. J. Energ. Res., 2014, 38, 466. https://doi.org/10.1002/er.3095

[46] Goldsmith J., Wong-Foy A., Cafarella M., Siegel D.: Chem.

Mater., 2013, 25, 3373. https://doi.org/10.1021/cm401978e

[47] Virji S., Kaner R.: J. Phys. Chem. B, 2006, 110, 22266.

https://doi.org/10.1021/jp063166g

[48] Conn C., Sestak S., Baker A., Unsworth J.: Electroanal., 1998, 10, 1137. https://doi.org/10.1002/(SICI)1521-

4109(199811)10:16<1137::AID-ELAN1137>3.0.CO;2-1

[49] Arsata R., Yub X., Li Y. et al.: Sensor. Actuator. B, 2009, 137, 529. https://doi.org/10.1016/j.snb.2009.01.028

[50] Yatsyshyn M., Zastavs'ka G., Gnizdyukh Y.: Visnyk Lviv Univ., 2014, 55, 413.

[51] Stetsiv Yu., Halushchak I., Yatsyshyn M., Serkiz R.: Visnyk Lviv Univ., 2016, 57, 418.

[52] Stetsiv Yu., Yatsyshyn M., Demchenko P., Serkiz R.: Visnyk

Lviv Univ., 2017, 58, 357.

[53] Hnizdiukh Yu., Yatsyshyn M., Reshetnyak O.: [in:]

Reshetnyak O., Zaikov G. (Eds.), Computational and Experimental

Analysis of Functional Materials. Apple Academic Press, CRC

Press (Taylor \& Francis Group), Toronto, New Jersey 2017, 423472.

[54] Vivekanandan J., Ponnusamy V., Mahudeswaran A.,

Vijayanand P.: Arch. Appl. Sci. Res., 2011, 3, 147.

[55] Guo H., He W., Lu Y., Zhang X.: Carbon, 2015, 92, 133.

https://doi.org/10.1016/j.carbon.2015.03.062

[56] Guo F., Liu Q., Mi H.: Mater. Lett., 2016, 163, 115.

https://doi.org/10.1016/j.matlet.2015.10.053

[57] Shi M., Bai M., Li B.: Mater. Lett., 2018, 212, 259.

https://doi.org/10.1016/j.matlet.2017.10.107

[58] Ho K., McKay G., Yeung K.: Langmuir, 2003, 19, 3019.

https://doi.org/10.1021/la0267084

[59] Fung L., Mei F., Lun Y.: Gold Bull., 2007, 40, 192.

https://doi.org/10.1007/BF03215580

[60] Xinqing C., Fung L., Qingian Z. et al.: J. Phys. Chem. C, 2009, 113, 9804. https://doi.org/10.1021/jp9018052

[61] Fung L., Xinqing C., Mei F., Yeung K.: Chem. Commun., 2008, 17, 2034. https://doi.org/10.1039/B719961A

[62] Loh X., Sairam M., Bismarck A. et al.: J. Membrane Sci., 2009, 326, 635. https://doi.org/10.1016/j.memsci.2008.10.045

[63] Yang C.-H., Wang T.-L., Shieh Y.-T.: Electrochem. Commun., 2009, 11, 335. https://doi.org/10.1016/j.elecom.2008.12.014 [64] Chandrakanthi N., Carem M.: Polym. Bull., 2000, 44, 101. https://doi.org/10.1007/s002890050579

[65] Zhang J., Liu C., Shi G.: J. Appl. Polym. Sci., 2005, 96, 732. https://doi.org/10.1002/app.21520

[66] Bhadra S., Khastgir D.: Polym. Degrad. Stabil., 2008, 93, 1094. https://doi.org/10.1016/j.polymdegradstab.2008.03.013

[67] Babazadeh M.: Iran. Polym. J., 2007, 16, 389.

[68] Ding L., Wang X., Gregory R.: Synthetic Met., 1999, 104, 73. https://doi.org/10.1016/S0379-6779(99)00035-1

[69] Bhadra S., Khastgir D.: Polym. Test., 2008, 27, 851.

https://doi.org/10.1016/j.polymertesting.2008.07.002

[70] Amano K., Ishikawa H., Kobayashi A. et al.: Synthetic Met., 1994, 62, 229. https://doi.org/10.1016/0379-6779(94)90210-0

[71] Pereira de Silva J., De Faria D., Cordoba de Torresi S.,

Temperini M.: Macromolecules, 2000, 33, 3077.

https://doi.org/10.1021/ma990801q

[72] Kieffel Y., Travers J., Ermolieff A., Rouchon D.: J. Appl. Polym. Sci., 2002, 86, 395. https://doi.org/10.1002/app.10981 [73] Trchova M., Matejka P., Brodinova J. et al.: Polym. Degrad. Stabil., 2006, 91, 114.

https://doi.org/10.1016/j.polymdegradstab.2005.04.022 
[74] Mathew R., Mattes B., Espe M.: Synthetic Met., 2002, 131, 141. https://doi.org/10.1016/S0379-6779(02)00177-7 [75] Ayad M., Abu El-Nasr A.: J. Phys. Chem. C, 2010, 114, 14377. https://doi.org/10.1021/jp103780w

[76] Ayad M., Abu El-Nasr A., Stejskal J.: J. Ind. Eng. Chem., 2012, 18, 1964. https://doi.org/10.1016/j.jiec.2012.05.012 [77] Ayad M., Zaghlol S.: Chem. Eng. J., 2012, 204-206, 79. https://doi.org/10.1016/j.cej.2012.07.102

[78] Jurczyk M., Kumar A., Srinivasan S., Stefanakos E.: Int. J. Hydrog. Energ., 2007, 32, 1010.

https://doi.org/10.1016/j.ijhydene.2006.07.012

[79] Titus E., Cabral G., Madaleno J. et al.:2007 NSTI

Nanotechnology Conference and Trade Show - NSTI Nanotech 2007, Technical Proceedings. USA, Santa Clara 2007, 1, 381.

[80] Wang P.-C., Dan Y., Liu L.-H.: Mater. Chem. Phys., 2014, 144, 155. https://doi.org/10.1016/j.matchemphys.2013.12.035 [81] Pham Q., Kim S.: Korean J. Chem. Eng., 2016, 33, 290. https://doi.org/10.1007/s11814-015-0122-y

[82] Stolarczyk A., Lapkowski M.: Synthetic Met., 2001, 121, 1385. https://doi.org/10.1016/S0379-6779(00)01453-3

[83] Hallik A., Alumaa A., Kurig H. et al.: Synthetic Met., 2007, 157, 1085. https://doi.org/10.1016/j.synthmet.2007.10.017

[84] Vernitskaya T., Efimov O.: Russ. Chem. Rev., 1997, 66, 443. https://doi.org/10.1070/RC1997v066n05ABEH000261

[85] Aleman C., Casanovas J., Torras J. et al.: Polymer, 2008, 49, 1066. https://doi.org/10.1016/j.polymer.2007.12.039

[86] Wang W., Li W., Ye J. et al.: Synthetic Met., 2010, 160, 2203. https://doi.org/10.1016/j.synthmet.2010.08.010

[87] Wysocka-Zołopa M., Winkler K.: Electrochim. Acta, 2017, 258, 1. https://doi.org/10.1016/j.electacta.2017.12.005

[88] Hakansson E., Lin T., Wang H., Kaynak A.: Synthetic Met., 2006, 156, 1194. https://doi.org/10.1016/j.synthmet.2006.08.006 [89] Wang X., Deng J., Duan X. et al.: Appl. Energ., 2015, 153, 70. https://doi.org/10.1016/j.apenergy.2014.10.040

[90] Lang X., Wan Q., Feng C. et al.: Synthetic Met., 2010, 160,

1800. https://doi.org/10.1016/j.synthmet.2010.06.023

[91] Germain J., Frecheta J., Svec F.: Chem. Commun., 2009, 1526. https://doi.org/10.1039/B821233C

[92] Lawal A., Wallace G.: Talanta, 2014, 119, 133.

https://doi.org/10.1016/j.talanta.2013.10.023
[93] Okan B., Zanjani J., Letofsky-Papst I. et al.: Mater. Chem. Phys., 2015, 167, 171. https://doi.org/10.1016/j.matchemphys.2015.10.027 [94] Attia N., Geckeler K.: Macromol. Rapid Comm., 2013, 34, 931. https://doi.org/10.1002/marc.201300060

[95] Wood C., Tan B., Trewin A. et al.: Chem. Mater., 2007, 19, 2034. https://doi.org/10.1021/cm070356a

[96] Buda C., Dunietz B.: J. Phys. Chem. B, 2006, 110, 10479. https://doi.org/10.1021/jp061249r

[97] Rowsell J., Eckert J., Yaghi O.: J. Am. Chem. Soc., 2005, 127, 14904. https://doi.org/10.1021/ja0542690

[98] Lochan R., Head-Gordon M.: Phys. Chem. Chem. Phys., 2006, 8, 1357. https://doi.org/10.1039/b515409j

[99] Li Y., Yang R.: J. Am. Chem. Soc., 2006, 128, 8136. https://doi.org/10.1021/ja061681m

[100] Jiang J., Su F., Trewin A. et al.: J. Am. Chem. Soc., 2008,

130, 7710. https://doi.org/10.1021/ja8010176

[101] Germain J., Svec F., Frechet J.: Chem. Mater., 2008, 20, 7069. https://doi.org/10.1021/cm802157r

[102] Fakirov S.: eXPRESS Polym. Lett., 2017, 11, 162.

https://doi.org/10.3144/expresspolymlett.2017.17

[103] Broom D., Hirscher M.: Energ. Environ. Sci., 2016, 9, 3368. https://doi.org/10.1039/C6EE01435F

Received: April 03, 2018 /Revised: May 23, 2018 / Accepted: September 12, 2018

\section{ФІЗИЧНА СОРБЦЯ МОЛЕКУЛЯРНОГО ВОДНЮ МІКРОПОРИСТИМИ ОРГАНІЧНИМИ ПОЛІМЕРАМИ}

Анотація. В огляді описані зииті та гіперзииті полімери, як матеріали з високою площею поверхні для адсорбиії великої кількості молекулярного водню. Зшиті поліанілін та поліпіррол використані як приклади адсорбиї̈ водню мікропористими органічними полімерами. Висвітлено основну причину фізичної сорбиії, щзо відбувається в мікропористих органічних полімерів, а також виклики на шляху налаштування значення ентальпї адсорбиії водню в межах 15-20 кДж/моль $\mathrm{H}_{2}$.

Ключові слова: гіперзииті полімери, мікропористі матеріали, фізична сорбиія, ентальпія адсорбиії водню. 